\title{
EXPERIENTIAL LEARNING PROCESSES USING AN E-DIARY IN STUDENTS' INTERNSHIP
}

\author{
Ilona Tandzegolskienė, \& Asta Lapėnienè \\ Academy of Education, Vytautas Magnus University, Kaunas (Lithuania)
}

\begin{abstract}
The article/presentation analyses data from e-diary taken by 88 students from three groups of pedagogical programs who were studying in the following school years: 2018-2019 and 2019-2020. As part of the internship tasks, the diary had to be written regularly weekly (for a total of 20 or 22 weeks). According to the provided half-standardised e-diary form, every week, the research participants had to document the most significant/successful/problematic situation in their school internship and raise any questions. The database on an e-diary basis contains 1962 situations of internship pedagogical activity. The data presented in the article is general for the whole group of research participants. The data analysis is based on six stages: access to the data, data coding, finding topics, revision of the topics, a summary of the topics and preparation of the report.

The article presents how the e-diary was designed and how the e-diary stimulates the metacognitive capacity to reflect upon thinking capacities. The thematic analysis of the entries in e-diary has been conducted according to the following three aspects: emotional, cognitive, and the change in internship activity. The thematic analysis's emotional aspect (which was revealed in the e-diary notes) has been reflected by the dynamics of satisfaction from the professional activity. The intellectual aspect has been revealed by the dynamics of changes in students' self-estimation, attitude towards learning, and the teaching profession. The diaries provided the opportunity to analyse the learning situations via descriptions in the e-diary and the participant's self-reflections on their gained internship experience.
\end{abstract}

Keywords: Experiential learning, diary structure, electronic diary, case study.

\section{Introduction}

Experiential learning is essential for the $21^{\text {st }}$ century. Experience can reshape the learner's future if it creates the possibility for conscious engagement. A connection between teachers' self-reflection and the metacognition of future teachers has been made clear. Self-reflection and metacognition provide important learning tools for building confidence and interpersonal skills since metacognitive knowledge enables future teachers to consciously apply learning strategies, develop effective work habits, and evaluate their performance (Desautel, 2009).

Nowadays, technologies are an integral part of the educational environment. The development of smart technologies and their integration into the teaching/learning process provides many perspectives and encourages the learner to reflect and think about the processes during student internships (Clipaa et al., 2012). E-diary is one of the most effective innovative tools for teachers to develop their teaching/learning practices and stimulates the metacognitive capacity (Clipaa et al., 2012; Bartlett \& Milligan, 2015). E-diary discloses realistic pictures of everyday school life and functions as a collection of 'instantaneous information in the authentic environment, which allows daily encounters to be captured and recorded during the internship. Therefore, the study based on the e-diary method is designed and organised only in collaboration with the study participants. This design requires the active involvement of research participants, which is essential to empower learners to be reflective teachers at the end of the internship. It also unites teachers as reflexive and self-supported technicians and responsible practitioners (Clipaa et al., 2012).

This article aims to reveal the benefits of constructing an electronic diary as an educational tool focusing on the observation and reflection of learning experiences.

Electronic diaries as a learning tool applied during organised pedagogical internships correlate with a constructivist approach to the study. The cognitive structure is constantly evolving and improving due to constructivism (Binkley \& Minor, 2020). A didactic attitude based on constructivism's principles emphasises learning as individual knowledge based on personal experience. Primary (ordinary, 
spontaneous) perception plays a mediator between the learner's knowledge and the totality of thinking structures (Bertran, 1995). The initial structure of perception constantly reforms itself to incorporate new knowledge into the learner's already existing cognitive structure. This new information is always affected and concurrently analysed according to the initial perception model and changing it (Binkley \& Minor, 2020). The purpose of constructivist learning is not to transmit and receive information, but to promote the learners' understanding and activity (Howard \& Brady, 2015), as learners independently construct and gather their knowledge base and become jointly responsible for the teaching content, which is inseparable from everyday life and experience. In response to this provision, an e-learning space is created with the help of an e-diary, where learners, while presenting their internship situations, have an opportunity to update gained internship experience and create new meanings based on it.

The E-diary design was based on Kolb's experiential learning model (Kolb, 1984; McLeod, 2017) by establishing connections between experience, learning environment, and pedagogical changes during the internship period. The essence of learning from experience is that learning and development are greatly facilitated by an integrated learning process based on the experiment, and it consists of the following crucial stages:

- $\quad$ here-and-now experience;

- data collection and naming, which includes observation and reflection;

- $\quad$ analysis and conceptualisation of the received information;

- $\quad$ concept verification process.

The learning specifics of using an e-diary are characterised by the fact that the emerging collaborative relationships strongly influence the transition from one stage to another based on this model in the e-learning space. Kolb and Fry (1975), emphases the main idea of the learning process, that is accompanied by tension and conflict. To obtain the four areas of the learning model is to gain new knowledge, abilities and skills. The experiential learning model is based on dialectical tension between the four types of interactions with the environment, which are the following: 1) During the first situation, direct experience an impression is formed, which enables the student to set certain during internship activity situations apart from the general stream of activities. Such experiences are usually caused by situations that contradict the established procedures in practical and intellectual activities. It depends on each specific situation, whether the experience is painful or pleasant. 2) In the second situation (observation and identification), the student records important internship activity experiences in the e-diary. It allows the student to look at his/her activity process as the observer reflecting over past events. In this situation, by describing his/her activity procedure, the student switches from the performer's position to a new activity observer position. 3) In the third situation (reflective activity assessment), the teacher/consultant, reacting to the described situation, mediates and helps the student reflect on his/her activity. 4) In the fourth situation, activity consultations during internships aim to search for deliberate activity prospects, and there is an attempt to foresee the alternatives to a specific activity.

These four teaching/learning situations create the prospect and the system of a consistent transition from direct experience to the planned activity, while each new teaching/learning situation enriches and expands previously gained experience. As a learning tool, e-diary allows students to perform various tasks and share their daily experiences and discoveries, which are later analysed and discussed. The description of problematic situations creates the preconditions for internship participants to move to the reflective assessment level to avoid the same mistakes in the future.

\section{Design/methodology}

For conducting this research were chosen participants from the Pedagogical Program. It is a one-year program that provides the qualification for successful graduates to start practising as teachers. The research was conducted in the following school years: 2018-2019 and 2019-2020. Research participants within the program have qualified to teach a particular subject (chemistry, physics, biology, languages, information technologies, mathematics, music, art, history, geography etc.) and complete their teacher qualification during the pedagogical studies.

Data were collected from 88 research participants (76 women and 12 men) who were part of the pedagogical program. For the most part, students in these studies already have pedagogical experience because they work in non-formal education or have started working in schools for the first academic year. E-diary was provided to the Lithuanian student participants who are part of the pedagogical program as school internships was a compulsory part of their study program. E-diary is the perfect tool for learners to teach and learn from it. In this research, the age and gender of research participants were not considered of distinct important. Research emphasises the analysis of the situation of internship activities of the research participants. The language of the research was Lithuanian, and all participants were participating in their native language. Since it plays an important role in constructing practitioners' identity and working on native language, they helped research participants reflect on themselves better (Kavaliauskienė et al., 2010). 
E-diary as a system of measures reflects two learning opportunities: Practice-functional and reflexive-conceptual, and its purpose during the pedagogical internships is twofold:

- For the beginner teachers - to capture internship activity situations and learn from them.

- To provide operative consulting support to study organisers for the novice educator.

E-diary function is divided into several stages. In the first stage, student participants were given access to the Moodle system and can fill in the e-diary questions for the whole week. Logged e-diary content can still be altered during the same week; however, e-diary content cannot be changed from the previous week.

In the second stage, the supervising teacher reads the participants' e-diaries from the specific week of their student participants' internship and note their supervisor comments and answers any noted questions. Comments can be written in the system only by the supervising teachers.

In the third stage, the data set collected based on the e-diary is analysed based on a set of semi-standardised thematic themes by the students themselves. Participating students independently analyse their described scenario of pedagogical activities during their internship. This process makes it possible to capture first-year teachers' activity regularities, which summarise the pedagogical internship experiences.

As part of the internship tasks, the diary had to be written regularly weekly (for a total of 20 or 22 weeks). Every week the student participants of the internship, according to the provided half-standardised e-diary form, had to describe in their opinion the most significant/successful/problematic situation in their school internship and to ask the questions they had. The questions were answered by the teachers working in that program. The students' mentors were involved in cases of specific problems. As a result, the system encourages research participants to record and analyse internship activity situations where and when developing in schools.

The e-diary entries were only available to a defined circle of users: the student and the teacher-consultant. Other students could only follow the entry if it were posted in a general discussion. The database on an e-diary basis contains 1962 situations of internship pedagogical activity. The data presented in the article are general for the whole group of research participants. The data analysis is based on six stages: access to the data, data coding, finding topics, revision of the topics, a summary of the topics and preparation of the report.

The thematic analysis of the entries in e-diary has been conducted according to the following three aspects: emotional, cognitive, and the change in internship activity. The emotional aspect of the thematic analysis- which was revealed in the e-diary notes- has been reflected as dynamics of satisfaction from the professional activity. The intellectual aspect has been revealed by the changing dynamics of the student's self-estimation, attitude towards learning, and the teaching profession. The internship experience side has been revealed by analysing the learning situations described in the e-diary and the student's reflections on the gained experience.

\section{The core experience of the interaction of structural elements}

The experiential learning situations showed certain personal, professional, and emotional aspects of development and how these aspects changed during the pedagogical internships in an e-diary (Figure 1).

Figure 1. Interaction of experience structure elements.

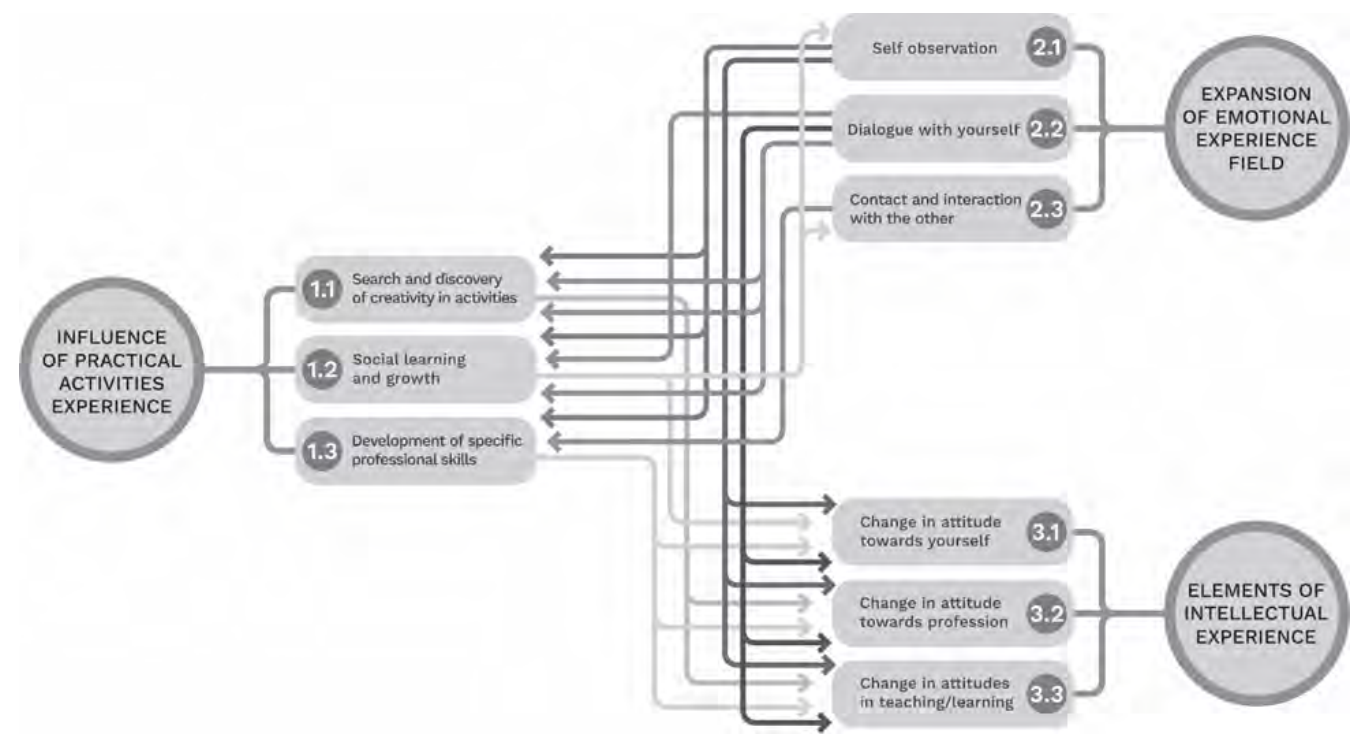


The main themes presented in the article also showed the interfaces and process flow. It is important to note that recorded and described activities during the internship raised awareness of ongoing processes. During the study, an individual's attitudes affected performance and learning. Situations containing rapid changes stimulate the student participants' emotions, which importantly links the learners' emotions to their learning experiences. As emotions fade with time and with the supervising mentors' supporting guidance, student participants' self-reported changes occur in both attitude and practice.

"In the first part of the internship, the observation was holistic. I observed and recorded everything that caused thoughts or questions. Now the observation does not feel like an acquired structure. I did not plan this deliberately, but I noticed the records improved organizationally" (Lina).

The review of results is an important stage in the development of an e-diary. Reflection and discussion with a mentor provided the opportunity to interact with others about one's experience and allow an educator to develop the knowledge and professional skills applicable to their profession. It shows that activity develops specific professional skills, and learners improve their communication skills.

"I am very happy with my mentor, thanks to whom I gained more self-confidence; I got acquainted with teaching methods she uses in lessons; I was able to learn new techniques of artistic expression; I was able to communicate and collaborate amicably. My mentor was always finding time with me to reflect on the subject. She has always been a kind, warm, and creative person" (Gintare).

During the research, e-diary's data was analysed and observed by study participants while describing problematic situations. They move to the reflexive assessment level independently, and this taught the young educators to develop a self-reflection algorithm and not repeat the same mistakes in the future. Knowledge gained during the internship also leads to personal growth, professional development, and the adoption of teaching/learning paradigms.

"The success, in my opinion, is that each week I was improving more and more during the internship. I started to notice my own mistakes and what I was seeking to change and improve, and I concluded each lesson with new demands made on myself. (Monika).

The e-diary questionnaire also aims to social learning and growing. It is achieved by observing and interpreting new experiences. Thus, its benefits alter the understanding of attitudes toward learning and professional change. Reading and analysing an e-diary showed that interns' physical, emotional, social, and intellectual environment was important.

"The most important thing in learning is to use existing knowledge, to formulate problems correctly, to organise one's own and students' work, to understand the goals and perspectives of one's work. What is more important for students is to assess their progress in educational activities." (Jurate).

Analysis of the situations presented in the documents showed that it was not always possible to move to the level of self-reflection. It required extensive guidance through the mentors' remarks to help trainee teachers respond and reflect on their observed and e-diary logged situations. The form created by the e-diary provides a quick response to the situation or problem that arises; the tool helps the student participant to gain a sense of discussion and constant support. Discussions in the e-diary platform aim not to provide an answer but to encourage the search for alternative solutions. For example, it has been suggested to observe other teachers' activities in the same problematic classrooms to exchange practices and consult one another. It has been demonstrated that discussion and peer collaboration construct new knowledge and experience, leading to personal development, professional growth, and pedagogical image building.

"I would like to ask what to do, for example, if a student misbehaves during a lesson, speaks out, does not do tasks, etc., and when you tell him or her, that after the lesson he or she will go to the principal to write an explanation, but he or she stubbornly says he or she will not go. What should teachers do in this case?" (Edita)

Using an e-diary as a tool helped the student participants capture emotions, insights, and experience elements during their internship. It prevents the loss of important details and enabled a deeper discussion and analysis of existing complex experiences and emotions. It is important to emphasise that both positive and negative emotions promote change in teachers practice work and intellectual change in attitudes. It inspires a mundane change in oneself as a personality and a professional activity that becomes more creative, planned, and analysed based on the didactic aspect.

\section{Discussion}

The e-diary becomes an important learning platform to capture real-life pictures of specific moments or individual and personalised descriptions of the daily routine. For consistency and completeness, it is essential to log both specific situations and to describe daily experience daily, so important emotional considerations are noted. Moreover, e-diary allows organic data to be collected by 
taking note of instant information. Based on this experience, we can conclude that an electronic diary is a good tool for retrieving pedagogical curriculum data and situations. Another advantage of e-diary documentation is that it allows submitting both texts for analysis and photos and visual samples. It can be assumed that the e-diary, as an independent tool, can also become a methodological tool and a special technique for researching and capturing educational processes in a specific research field.

\section{Conclusion}

1. The experiential learning model was implemented by creating a system of measures for newly qualified teachers, aiming to systematically record, reflectively, observe and analyse specific situation during internship activities. This system of measures comprises an e-diary form, support-consulting system and online half standardised form of e-diary analysis. This system's relevance has become especially evident when qualifying face new, unusual internship activity situations and when the existing experience is insufficient, nor is there enough knowledge to deal with them.

2. E-diary, as the system of learning tools, has presents opportunities to systematically cover all experiential learning stages: observation and identification of the experienced situation; reflective assessment of the activity and the change in internship activity. Identification of problematic situation often contributed to finding solutions for them. The analysis of the situations recorded in the e-diary has made it possible to identify event development tendencies and forecast the practitioner's behaviour changes. Reacting to the experiences recorded in the e-diary, the future teacher encourages reflecting, searching for alternative solutions and foreseeing possibilities of changes in a specific professional activity, which leads to growth as a professional.

\section{References}

Bartlett, R. \& Milligan, Ch. (2015). What is Diary Method? London: Bloomsbury Academic.

Bertran, I. (1995). Contemporary Theories and Practice in Education. Madison: Atwood Publishing.

Binkley, E., E. \& Minor, A. J. (2020). Constructivist Pedagogy to Promote Cultural Learning in Counselor Education. Journal of Creativity in Mental Health, 1-12.

Braun, V., Clarke, V. \& Terry, G. (2014). Thematic analysis. In P. Rohleder \& A. Lyons (Eds.) Qualitative research in clinical and health psychology. Basingstoke: Palgrave MacMillan.

Clipaa, O., Ignata, A. \& Stansiub, M. (2012). Learning diary as a tool for metacognitive strategies Development. Published by Elsevier B.V. Selection and/or peer-review under responsibility of PSIWORLD2011, 905-909.

Desautel, D. (2009). Becoming a Thinking Thinker: Metacognition, Self-Reflection, and Classroom Practice. Teachers College Record, Vol. 111(8), 1997-2020.

Dewey, J. (1959). Art as Experience and Nature. New York: Capricorn. Dewey on education: selections. New York: Teachers College Press.

Dobos, A. (2014). Experiential learning for professional development in the civil service. Procedia-Social and Behavioral Sciences, Vol. 116, 5085-5090.

Howard, C. \& Brady, M. (2015) Teaching social research methods after the critical turn: challenges and benefits of a constructivist pedagogy, International Journal of Social Research Methodology, Vol.18(5), 511-525.

Jyi-Yeon, Y. (2008). The Use of Diaries as a Qualitative Research Method to Investigate Teachers` Perception and Use of Rating Schemes. Journal of Pan-Pacific Association of Applied Linguistics, Vol. 12(1), 1-10.

Kavaliauskienė G., Mažeikienė V., \& Valūnaitė-Oleškevičienė G. (2010). Role of native language in learning English. Filologija. Edukologija, Vol. 18 (2).

Kolb, D., A. (1984) Experiential Learning. Experience as the Source of Learning and Development. New Jersey: Prentice-Hall.

Kozulin, A. \& Rand, Y. (Ed.) (2000). Experience of Mediated Learning. An Impact of Feuerstein's Theory in Education and Psychology. Amsterdam: Pergamon.

McLeod, S. A. (2017). Kolb - learning styles and experiential learning cycle. Simply Psychology. https://www.simplypsychology.org/learning-kolb.html.

Rutkauskienè, D., Lenkavičius, A., Targamadzè, A., Volunevičienè, A, Pociūtè, E., Dėmenienè, A. \& Kelmenienè, V. (2007). Nuotolinio mokymosi dėstytojo vadovas. Mokomoji knyga. Kaunas: Technologija.

Schitz, B., Klug, J. \& Schmidt, M. (2011). Assessing Self-Regulated Learning Using Diary Measures with University Students Handbook of Self-Regulation of Learning and Performance. New York and London: Routledge, $251-259$.

Žydžiūnaitė, V. \& Sabaliauskas, S. (2017). Kokybiniai tyrimai: principai ir metodai. Vilnius: Vaga, 207-228. 